\title{
Ockham's razor defeated: about two atypical cases of hemolytic uremic syndrome
}

\author{
Chloe Schwarz ${ }^{1 *} \mathbb{D}$, Alice Brehon², Cyril Mousseaux¹, Yosu Luque', Patricia Senet ${ }^{2}$, Patricia Mariani $^{3}$, \\ Inna Mohamadou', Lara Zafrani ${ }^{4}$, Véronique Frémeaux-Bacchi ${ }^{5}$, Eric Rondeau', David Buob ${ }^{6}$ and Cédric Rafat ${ }^{1}$
}

\begin{abstract}
Background: Medical investigation is a favorite application of Ockham's razor, in virtue of which when presented with competing hypotheses, the solution with the fewest assumptions should be privileged. Hemolytic uremic syndrome (HUS) encompasses diseases with distinct pathological mechanisms, such as HUS due to shiga-like toxinproducing bacteria (STEC-HUS) and atypical HUS, linked to defects in the alternate complement pathway. Other etiologies such as Parvovirus B19 infection are exceptional. All these causes are rare to such extent that we usually consider them mutually exclusive. We report here two cases of HUS that could be traced to multiple causes.

Cases presentation: Case 1 presented as vomiting and diarrhea. All biological characteristics of HUS were present. STEC was found in stool (by PCR and culture). After initial remission, a recurrence occurred and patient was started on Eculizumab. Genetic analysis revealed the heterozygous presence of a CFHR1/CFH hybrid gene. The issue was favorable under treatment.

In case 2, HUS presented as fever, vomiting and purpura of the lower limbs. Skin lesions and erythroblastopenia led to suspect Parvovirus B19 primo-infection, which was confirmed by peripheral blood and medullar PCR. Concurrently, stool culture and PCR revealed the presence of STEC. Evolution showed spontaneous recovery.

Conclusions: Both cases defy Ockham's razor in the sense that multiple causes could be traced to a single outcome; furthermore, they invite us to reflect on the physiopathology of HUS as they question the classical distinction between STEC-HUS and atypical HUS. We propose a two-hit mechanism model leading to HUS. Indeed, in case 1, HUS unfolded as a result of the synergistic interaction between an infectious trigger and a genetic predisposition. In case 2 however, it is the simultaneous occurrence of two infectious triggers that led to HUS. In dissent from Ockham's razor, an exceptional disease such as HUS may stem from the sequential occurrence or cooccurrence of several rare conditions.
\end{abstract}

Keywords: HUS, STEC, Physiopathology, aHUS, Parvovirus B19, Case report

\footnotetext{
* Correspondence: chloe.schwarz@gmail.com

'Service d'urgences néphrologiques et transplantation rénale, hôpital Tenon, Paris, France

Full list of author information is available at the end of the article
}

(c) The Author(s). 2020 Open Access This article is licensed under a Creative Commons Attribution 4.0 International License, which permits use, sharing, adaptation, distribution and reproduction in any medium or format, as long as you give appropriate credit to the original author(s) and the source, provide a link to the Creative Commons licence, and indicate if changes were made. The images or other third party material in this article are included in the article's Creative Commons licence, unless indicated otherwise in a credit line to the material. If material is not included in the article's Creative Commons licence and your intended use is not permitted by statutory regulation or exceeds the permitted use, you will need to obtain permission directly from the copyright holder. To view a copy of this licence, visit http://creativecommons.org/licenses/by/4.0/ The Creative Commons Public Domain Dedication waiver (http://creativecommons.org/publicdomain/zero/1.0/) applies to the data made available in this article, unless otherwise stated in a credit line to the data. 


\section{Background}

Scientific investigation is a favorite application of William Ockham's lex parsimonia by virtue of which "Entia non sunt multiplicanda praeter necessitatem" or in other words "More things should not be used than are necessary”. Although there are numerous formulations of this principle, a widely accepted clinical corollary is that when contemplating multiple competing hypotheses, the one with the fewest assumptions is to be privileged. Hemolytic uremic syndrome (HUS) is a rare and complex clinical syndrome defined by thrombocytopenia, non-immune microangiopathic hemolytic anemia, and acute kidney injury [1]. Shiga-like toxin-producing bacteria (STEC) represents the most common form of HUS, yet it remains a rare occurrence with an estimated incidence in the European Union of 1.7 cases per $10^{5}$ patient.years (http://ecdc.europa.eu/en/ publications/Publications/food-and-waterborne-diseasessurveillance-report-2015.pdf). In comparison, atypical hemolytic uremic syndrome (aHUS), a complement mediated disease, is even more infrequent with a reported estimated incidence of 0.23 per year per $10^{6}$ people in the French population [2]. In fact, the spectrum of HUS encompasses a myriad of other etiologies, many being exceptional and merely supported by a handful of case reports and a plausible biological rationale. Such is the case of parvovirus B19, a virus with a distinct tropism for the endothelium which has been acknowledged as a rare cause of HUS [3-5]. In agreement with Ockham's razor, it may be posited that the likelihood of a case of HUS having more than one cause is very poor and, correlatively, that the confident identification of one cause may obviate the need for further etiological investigation. Herein we describe two cases of HUS that defy Ockham's razor to the extent that both cases could be traced to multiple causes.

\section{Cases presentation \\ Case 1}

A 34-year-old male patient with an unremarkable medical history consulted his local emergency department for intractable emesis for the past $48 \mathrm{~h}$. The day before, he had been given a diagnosis of hand, mouth and feet syndrome with a possible cross-transmission from his 4year-old daughter. He had a single bout of non-bloody diarrhea. Notable clinical signs consisted in elevated blood pressure $(167 / 98 \mathrm{mmHg})$, purpura of the lower limbs and papulovesicular acrodermatitis of both hands and wrists. Prominent biological abnormalities consisted of KDIGO stage 3 AKI (Blood urea: $30 \mathrm{mmol} / \mathrm{L}$ plasma creatinine: $497 \mu \mathrm{mol} / \mathrm{L}$ ) and hematological thrombotic microangiopathy (TMA) (hemoglobin levels: $13.1 \mathrm{~g} / \mathrm{dL}$, platelets: $47000 / \mathrm{mm}^{3}$, haptoglobin levels $<0.20 \mathrm{~g} / \mathrm{dl}$, greatly elevated LDH levels: $1843 \mathrm{UI} / \mathrm{L}$ and schistocytes were detected). Proteinuria was in the nephrotic range $(6 \mathrm{~g} / 24 \mathrm{~h})$, consisted primarily of albumin (66\%) and was associated with microscopic hematuria upon urine culture. The patient was referred to an intensive care department and was started immediately on plasma exchange (PE). Neurological examination was normal. After two rounds, PE were discontinued owing to normal ADAMTS13 activity (113\%). Additional etiological workup included negative HIV, HBV, HCV testing, unremarkable lymphocyte immunophenotyping and normal levels of $\mathrm{C} 3, \mathrm{C} 4$ and $\mathrm{CH} 50$. He was next referred to our renal intensive care unit. Quantitative explorations of the alternate complement pathway (ACP) disclosed normal levels of MCP, Factor $\mathrm{H}$ and Factor I and negative testing for anti-FH antibodies. Accordingly, renal biopsy identified double contours and several foci of mesangiolysis as well as focal segmental glomerulosclerosis of the tip variant affecting one glomerulus (Fig. 1). Following supportive care with rehydration and blood pressure control, signs of peripheral TMA resolved while plasma creatinine levels declined to $350 \mu \mathrm{mol} / \mathrm{L}$. The presence of shigatoxin $(s t \times 2 b)$ and hemolysin (ehxa) were detected via PCR assessment in the stool samples and stool culture confirmed the presence of the enterohemorrhagic O128 Escherichia coli clone. Together these results ruled in favor of STEC-HUS. One month later the patient was readmitted in our unit owing to the recurrence of peripheral thrombotic microangiopathy (platelets: 130000/mm3, Hemoglobin: haptoglobin < $0.01 \mathrm{~g} / \mathrm{dl}$, schistocytes: $1 \%, \mathrm{LDH}: 740 \mathrm{UI} / \mathrm{L})$ and AKI with a creatinine level of $470 \mu \mathrm{mol} / \mathrm{L}$. Repeated stool culture did not find evidence for the persistence of the predetermined E. coli clone or shigatoxin. Due to gradual worsening of the kidney function and platelet levels the patient was empirically started on eculizumab

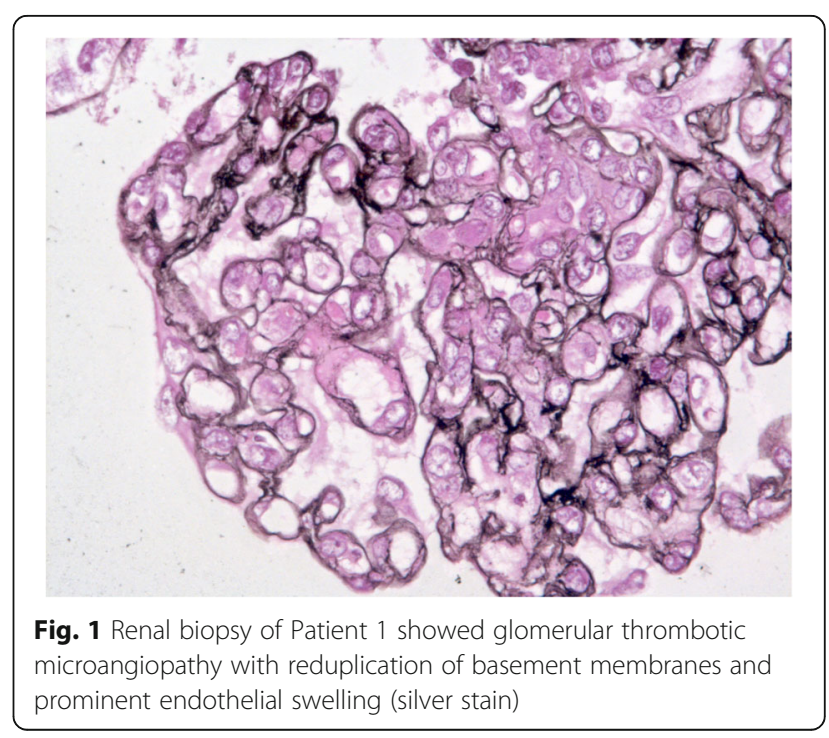


pending genetic findings. In the course of 15 days, creatinine levels gradually decreased from $630 \mu \mathrm{mol} / \mathrm{L}$ to $193 \mu \mathrm{mol} / \mathrm{L}$ and signs of TMA resolved. Genetic testing revealed that the patient was a heterozygous carrier of a CFHR1/CFH hybrid gene demonstrated to be associated with aHUS [6]. An attempt to discontinue eculizumab therapy 9 months after its initiation resulted in a second recurrence with an increase of creatinine levels to $430 \mu \mathrm{mol} / \mathrm{L}$ along with overt signs of peripheral TMA. After resuming eculizumab therapy, TMA resolved once again and creatinine levels fell back to baseline levels.

\section{Case 2}

A 44-year-old male patient presented to the emergency department with fever and skin lesions. His only past medical history consisted of IV drug abuse, discontinued for several years and under substitution therapy by buprenorphin. He reported over the past 2 weeks fever, emesis, myalgia, ankle arthralgia, headache and asthenia. Clinical examination noted a purpura located on the feet and distal legs (Fig. 2). Blood pressure was $120 / 86 \mathrm{mmHg}$. First blood tests only revealed mild thrombocytopenia (120, $000 / \mathrm{mm} 3)$ and creatinine levels were normal $(98 \mu \mathrm{mol} / \mathrm{L})$. He was referred to our nephrological department 4 days later due to the subsequent development of a rapidly progressive acute kidney injury. Upon admission he presented KDIGO stage 3 AKI (serum creatinine: $404 \mu \mathrm{mol} / \mathrm{L}$, BUN: $43 \mathrm{mmol} / \mathrm{L}$ ) with microscopic hematuria and glomerular range proteinuria $(2 \mathrm{~g} / 24 \mathrm{~h})$ and signs of hematological TMA (Platelets 71,000/mm3, hemoglobin level: $10 \mathrm{~g} / \mathrm{dL}$, haptoglobin $<0.08 \mathrm{~g} / \mathrm{L}$, LDH $864 \mathrm{U} / \mathrm{L}$, detection of schistocytes $1.7 \%$, reticulocytes $12,000 / \mathrm{mm} 3$ ). Blood pressure remained normal, as well as neurological examination. No diarrhea was reported. Platelet levels spontaneously normalized within $24 \mathrm{~h}$. A renal biopsy was performed, showing marked glomerular endotheliosis without evidence of microthrombi; no cellular proliferation was noted.

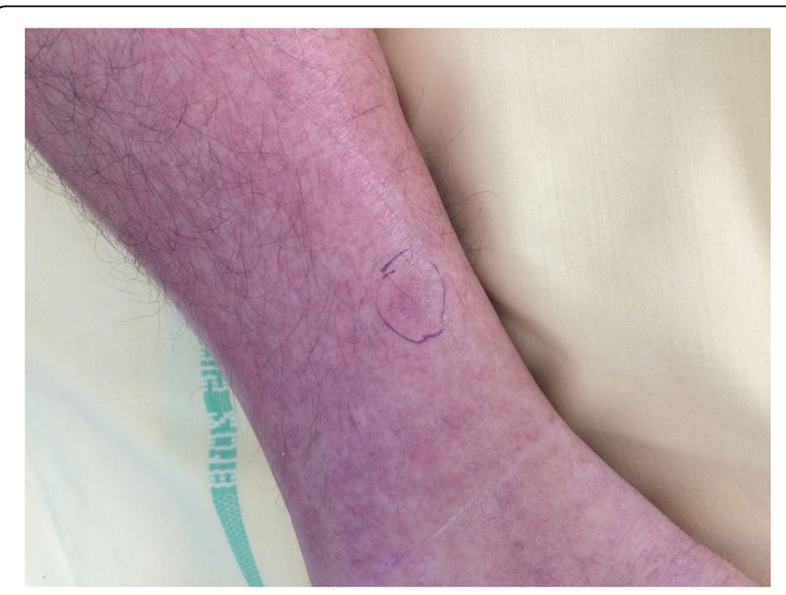

Fig. 2 Patient 2 presented with a palpable purpura of legs
Other biological investigations included negative testing for HIV, HBV, and HCV, mildly decreased levels of C3 $(0.8 \mathrm{~g} / \mathrm{L})$ and $\mathrm{C} 4(0.19 \mathrm{~g} / \mathrm{L})$ serum complement levels, and negative ANCA. Owing to the aregenerative character of anemia, a bone marrow exam was performed; it showed erythroblastopenia and no other cytological abnormality. A skin biopsy was also realized and revealed purpuric capillaritis without vasculitis. Parvovirus B19 was detected both in the plasma $(6.07 \mathrm{log})$ and in the bone marrow biopsy. Parvovirus B19 serology disclosed positive anti-B19 IgM (34 UI/L) and IgG antibodies (23 UI/L).

Taken together the clinical and biological presentation was suggestive of Parvovirus B19 primo-infection. However, stool sample culture found the presence of enterohemorragic O26 Escherichia coli confirmed by PCR which was positive for $s t x 1 b$ (shigatoxin gene), eae (adhesion gene) and ehxa (hemolysin gene). The patient spontaneously and rapidly improved with normalization of platelets within 7 days. One month later, patient had clinically fully recovered, hemoglobin and platelets levels were normal, serum creatinine was $58 \mu \mathrm{mol} / \mathrm{L}$ with no significant proteinuria; isolated microscopic hematuria persisted.

\section{Discussion and conclusion}

Both cases of HUS presented here, and summarized in Table 1, could be traced to more than one etiology. HUS is a rare entity for which the classical nosological definition accepts on one side typical or STEC-HUS, which is preceded by bloody diarrhea and is a one-time disease, and on the other side aHUS, linked to defects in the regulation of the $\mathrm{ACP}$, which is typically prone to recurrences in the absence of treatment. The distinction between these two entities is purportedly based on different clinical presentations but ultimately the final diagnosis relies on isolation of shiga-like toxin producing E.coli strain on the one hand, and identification of genetically based or acquired complement pathway alteration on the other. Of note, pathogenic variants of the complement system and anti-CFH auto-antibodies only account for 60 to $65 \%$ of the total cases of aHUS. DGKE pathogenic variants are reported in an extra 3\% of the cases which leaves more than $30 \%$ of aHUS cases undocumented based on current genetic testing [2, 7]. Pending conclusive physiopathology-based investigations, both conditions appear to overlap to the point where they are indiscernible from a bedside standpoint. In lieu of this classical separation in two distinct entities, we argue that in case 1 HUS unfolded as a two-hit mechanism, driving the activation of the $\mathrm{ACP}$ and the formation of microthrombi, STEC acting here as one of the most potent among different possible triggers to this condition. Indeed, next to aHUS, STEC-HUS has been shown to involve the alternate pathway complement [8]. Stx2 has been shown in vitro to interfere with ACP 
Table 1 Summary of clinical and biological characteristics of Cases 1 and 2

\begin{tabular}{|c|c|c|}
\hline & Patient 1 & Patient 2 \\
\hline Clinical presentation & $\begin{array}{l}\text { No fever } \\
\text { Elevated blood pressure } \\
\text { Vomiting and diarrhea } \\
\text { Skin purpura }\end{array}$ & $\begin{array}{l}\text { Fever } \\
\text { Normal blood pressure } \\
\text { Vomiting, no diarrhea } \\
\text { Skin purpura } \\
\text { Arthralgia and myalgia }\end{array}$ \\
\hline Biological presentation & $\begin{array}{l}\text { KDIGO stage } 3 \mathrm{AKI} \\
\text { Proteinuria } 6 \mathrm{~g} / 24 \mathrm{~h} \\
\text { Microscopic haematuria } \\
\text { Hemoglobin } 13.1 \mathrm{~g} / \mathrm{dL} \\
\text { Platelets } 47,000 / \mathrm{mm} 3 \\
\text { Schistocytes } 1 \% \\
\mathrm{LDH} 740 \mathrm{UI} / \mathrm{L}\end{array}$ & $\begin{array}{l}\text { KDIGO stage } 3 \mathrm{AKI} \\
\text { Proteinuria } 2 \mathrm{~g} / 24 \mathrm{~h} \\
\text { Microscopic haematuria } \\
\text { Hemoglobin } 10 \mathrm{~g} / \mathrm{dL} \\
\text { Platelets } 71,000 / \mathrm{mm} 3 \\
\text { Schistocytes } 1.7 \% \\
\mathrm{LDH} 864 \mathrm{UI} / \mathrm{L}\end{array}$ \\
\hline Complement exploration & $\begin{array}{l}\text { Normal C3 } \\
\text { Normal C4 } \\
\text { Normal Factor H, Factor I, MCP } \\
\text { Absence of anti-Factor H antibodies }\end{array}$ & $\begin{array}{l}\text { Moderately low C3 } \\
\text { Normal C4 } \\
\text { Normal Factor H, Factor I, MCP } \\
\text { Absence of anti-Factor H antibodies }\end{array}$ \\
\hline Microbiological evidence of STEC & $\begin{array}{l}\text { Stool culture positive for E. coli O128 serotype } \\
\text { PCR positive for st } x 2 b \text { and ehxa genes }\end{array}$ & $\begin{array}{l}\text { Stool culture positive for E. coli O26 serotype } \\
\text { PCR positive for stx } 1 a \text {, eae and ehxa genes }\end{array}$ \\
\hline Other cause of HUS & Presence of a heterozygous CFHR1/CFH hybrid gene & Parvovirus B19 primo-infection \\
\hline Recurrence & Yes & No \\
\hline
\end{tabular}

regulation by binding factor $\mathrm{H}$ [9]. Furthermore Stx2 induces the expression of P-selectin on human microvascular endothelial cell surface, which binds and activates C3 via the alternate pathway, leading to thrombi formation in a murine model of STEC-HUS [10].

This two-hit mechanism model is grounded in the concept of a synergic interaction between an infectious trigger and a predisposing genetic background. Accordingly, two cases of STEC-HUS have been reported in a 4-year old child and an 18-month infant, both shown to carry MCP mutations. The outcome proved fatal in the former case while eculizumab resulted in protracted remission in the latter $[11,12]$. Similarly, Alberti et al. reported two additional cases of STEC-HUS resulting in ESRD, yet, post-transplantation recurrence of HUS revealed a mutation of CFI and MCP respectively [13].

However, a recent series by Frémeaux-Bacchi et al addressed this issue in the pediatric setting [14]: if it did not yield a higher rate of pathological variants related to ACP genes in the STEC-HUS population than in the general population (17\% vs $14 \%)$, it did unravel a significantly higher frequency of very rare pathogenic variants in the STEC-HUS cohort ( $4 \%$ vs $0.8 \%$ ).

Another model for this two-hit mechanism is the occurrence of two concurrent infectious triggers, which is deemed to be the likely scenario in case 2. Parvovirus B19 has been implicated in various renal manifestations, namely proliferative glomerulonephritis, collapsing glomerulopathy or focal segmental glomerulosclerosis as well as TMA [15]: one occurrence ascribed to parvovirus B19 primo-infection in a healthy adult was related by Prasad et al [3]; the clinical presentation was particularly severe resulting in permanent chronic dialysis. Parvovirus B19 has also been found responsible of TMA in kidney recipient patients [4, 16]. From a physiopathological standpoint, the hypothesis that Parvovirus B19 can cause TMA is supported by its tropism for the endothelial cell: direct infection and injury is permitted by the presence on the endothelial cell's surface of the P antigen, which acts as a receptor for the virus and is found in the kidney $[15,17]$. Of note, glomerular endotheliosis, the prevailing pathological finding in case 2, is both a prominent lesion in TMA and a recognized feature of parvovirus B19 renal injury $[5,18]$.

Another approach to these cases is foreseen in the words of Walter Chatton: "Consider an affirmative proposition, which, when it is verified, is verified only for things; if three things do not suffice for verifying it, one has to posit a fourth, and so on in turn [for four things, or five, etc.]". (Reportatio I, 10-48, paragraph 57, p. 237). In case 1 STEC-HUS could not account for the relapse of TMA which occurred several weeks after the initial event. Neither could STEC-HUS be held responsible for the skin manifestations in case 2 . On a more general note, a novel concept has emerged from the ever-expanding list of pathogenic variants affecting the complement or other pathways whereby HUS stems from the interaction between a trigger (infectious, immunological or toxic) and a predisposing genetic background. Herein, STEC-HUS assumed a dual role as the most powerful trigger foreseeable and a direct cause of HUS per se. In case 2, it may be surmised that HUS resulted from the combined aggression of parvovirus B19 and STEC. In each case, these reports provide ground for a model of HUS physiopathology involving a two-hit mechanism. At any rate, they highlight the need for clinicians to entertain the prospect for an additional cause of HUS whenever the clinical picture or the course appears at odds with the initial etiological diagnosis of TMA. 


\section{Abbreviations}

ACP: Alternate complement pathway; aHUS: Atypical hemolytic uremic syndrome; AKI: Acute kidney injury; ESRD: End-stage renal disease; HBV: Hepatitis B virus; HCV: Hepatitis C virus; HIV: Human immunodeficiency virus; HUS: Hemolytic uremic syndrome; LDH: Lactate dehydrogenase; PE: Plasma exchange; STEC: Shiga-like toxin-producing bacteria; STECHUS: Hemolytic uremic syndrome caused by Shiga-like toxin-producing bacteria; TMA: Thrombotic microangiopathy

\section{Acknowledgements}

Not applicable.

\section{Authors' contributions}

CS and CR wrote the manuscript. AB and PS contributed to the dermatologic assessment and illustrations of case 2. DB contributed to the anatomopathologic aspects and illustrations of both cases. VFB provided expert immunological and genetic assessment. PM provided microbiological expert assessment. LZ carried out initial ICU management in both cases. CS, $\mathrm{CR}, \mathrm{IM}, \mathrm{CM}, \mathrm{YL}$ and $\mathrm{ER}$ attended to patient 1 and/or patient 2 in the Nephrology department. In addition, IM and CM were involved in data acquisition and analysis, YL provided significant contribution to the article design and the elaboration of the draft and ER provided expertise in the analysis and appraisal of the clinical and pathological data related to both cases. All authors read and approved the final manuscript.

\section{Funding}

None.

\section{Availability of data and materials}

Data sharing is not applicable to this article as no datasets were generated or analysed during the current study.

\section{Ethics approval and consent to participate}

Not applicable.

\section{Consent for publication}

Written consent was obtained from both patients before publication.

\section{Competing interests}

The authors declare that they have no competing interests.

\section{Author details}

'Service d'urgences néphrologiques et transplantation rénale, hôpital Tenon, Paris, France. ${ }^{2}$ Service de dermatologie, hôpital Tenon, Paris, France. ${ }^{3}$ Service de microbiologie, hôpital Robert Debré, Paris, France. ${ }^{4}$ Service de Médecine Intensive et Réanimation, hôpital Saint Louis, Paris, France. ${ }^{5}$ Service d'immunologie, Hôpital Européen Georges Pompidou, Paris, France. 'Service d'anatomopathologie, hôpital Tenon, Paris, France.

Received: 7 February 2020 Accepted: 2 July 2020

Published online: 11 July 2020

\section{References}

1. Mele C, Remuzzi G, Noris M. Hemolytic uremic syndrome. Semin Immunopathol Juill. 2014;36(4):399-420.

2. Fremeaux-Bacchi V, Fakhouri F, Garnier A, Bienaimé F, Dragon-Durey M-A, Ngo S, et al. Genetics and outcome of atypical hemolytic uremic syndrome: a nationwide French series comparing children and adults. Clin J Am Soc Nephrol. 2013;8(4):554-62.

3. Prasad B, St Onge J. Parvovirus leading to thrombotic microangiopathy in a healthy adult. BMJ Case Rep. 2016;2016:bcr2015213492.

4. Ardalan MR, Shoja MM, Tubbs RS, Jayne D. Parvovirus B19 microepidemic in renal transplant recipients with thrombotic microangiopathy and allograft vasculitis. Exp Clin Transplant. 2008;6(2):137-43.

5. Subramanya A, Houghton D, Watnick S. Steroid-responsive idiopathic glomerular capillary endotheliosis: case report and literature review. Am J Kidney Dis. 2005;45(6):1090-5.

6. Valoti E, Alberti M, Tortajada A, Garcia-Fernandez J, Gastoldi S, Besso L, et al. A novel atypical hemolytic uremic syndrome-associated hybrid CFHR1/CFH gene encoding a fusion protein that antagonizes factor $\mathrm{H}$-dependent complement regulation. J Am Soc Nephrol. 2015;26(1):209-19.
7. Bu F, Zhang Y, Wang K, Borsa NG, Jones MB, Taylor AO, et al. Genetic analysis of 400 patients refines understanding and implicates a new gene in atypical hemolytic uremic syndrome. J Am Soc Nephrol. 2018;29(12):2809-19.

8. Noris M, Mescia F, Remuzzi G. STEC-HUS, atypical HUS and TTP are all diseases of complement activation. Nat Rev Nephrol. 2012;8(11):622-33.

9. Poolpol K, Orth-Höller D, Speth C, Zipfel PF, Skerka C, de Córdoba SR, et al. Interaction of Shiga toxin 2 with complement regulators of the factor $\mathrm{H}$ protein family. Mol Immunol. 2014;58(1):77-84.

10. Morigi M, Galbusera M, Gastoldi S, Locatelli M, Buelli S, Pezzotta A, et al. Alternative pathway activation of complement by Shiga toxin promotes exuberant C3a formation that triggers microvascular thrombosis. J Immunol. 2011;187(1):172-80.

11. Fang CJ, Fremeaux-Bacchi V, Liszewski MK, Pianetti G, Noris M, Goodship $T H J$, et al. Membrane cofactor protein mutations in atypical hemolytic uremic syndrome (aHUS), fatal Stx-HUS, C3 glomerulonephritis, and the HELLP syndrome. Blood. 2008;111(2):624-32.

12. Caillaud C, Zaloszyc A, Licht C, Pichault V, Frémeaux-Bacchi V, Fischbach M. CFH gene mutation in a case of Shiga toxin-associated hemolytic uremic syndrome (STEC-HUS). Pediatr Nephrol. 2016;31(1):157-61.

13. Alberti M, Valoti E, Piras R, Bresin E, Galbusera M, Tripodo C, et al. Two patients with history of STEC-HUS, posttransplant recurrence and complement gene mutations. Am J Transplant. 2013;13(8):2201-6.

14. Frémeaux-Bacchi V, Sellier-Leclerc AL, Vieira-Martins P, Limou S, Kwon T, Lahoche A, et al. Complement gene variants and Shiga toxin-producing Escherichia coli-associated hemolytic uremic syndrome: retrospective genetic and clinical study. Clin J Am Soc Nephrol. 2019:14(3):364-77.

15. Waldman M, Kopp JB. Parvovirus B19 and the kidney. Clin J Am Soc Nephrol. 2007;2(Suppl 1):S47-56.

16. Murer L, Zacchello G, Bianchi D, et al. Thrombotic microangiopathy associated with parvovirus B 19 infection after renal transplantation. J Am Soc Nephrol. 2000;11(6):1132-7.

17. Cooling LL, Koerner TA, Naides SJ. Multiple glycosphingolipids determine the tissue tropism of parvovirus B19. J Infect Dis. 1995;172(5):1198-205.

18. Takeda S, Takaeda C, Takazakura E, Haratake J. Renal involvement induced by human parvovirus B19 infection. Nephron. 2001;89(3):280-5.

\section{Publisher's Note}

Springer Nature remains neutral with regard to jurisdictional claims in published maps and institutional affiliations.

\section{Ready to submit your research? Choose BMC and benefit from}

- fast, convenient online submission

- thorough peer review by experienced researchers in your field

- rapid publication on acceptance

- support for research data, including large and complex data types

- gold Open Access which fosters wider collaboration and increased citations

- maximum visibility for your research: over $100 \mathrm{M}$ website views per year

At BMC, research is always in progress.

Learn more biomedcentral.com/submissions 